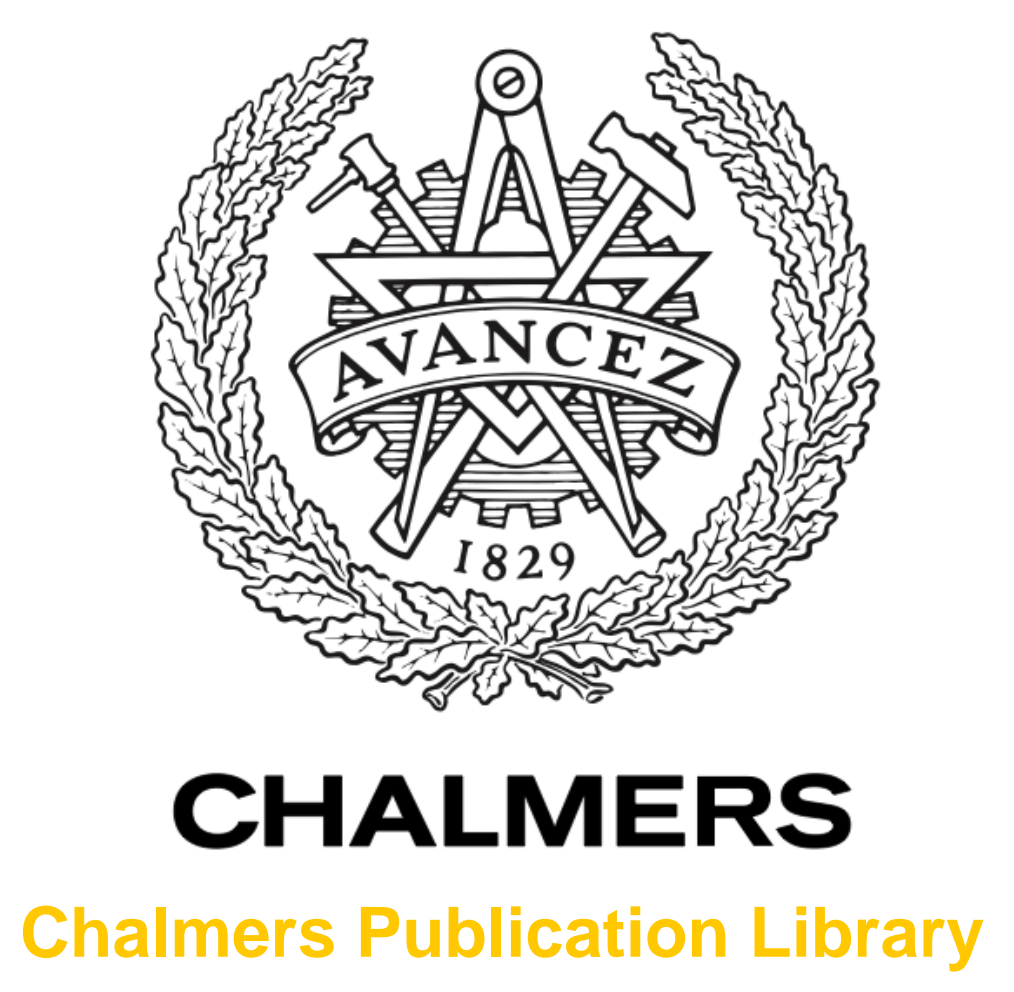

\title{
Ionic Liquids as Precatalysts in the Highly Stereoselective Conjugate Addition of ,- Unsaturated Aldehydes to Chalcones
}

This document has been downloaded from Chalmers Publication Library (CPL). It is the author's version of a work that was accepted for publication in:

Chemistry - A European Journal (ISSN: 0947-6539)

Citation for the published paper:

Ta, L. ; Axelsson, A. ; Bijl, J. et al. (2014) "Ionic Liquids as Precatalysts in the Highly Stereoselective Conjugate Addition of ,-Unsaturated Aldehydes to Chalcones". Chemistry A European Journal, vol. 20(43), pp. 13889â13893.

http://dx.doi.org/10.1002/chem.201404288

Downloaded from: http://publications.lib.chalmers.se/publication/204508

Notice: Changes introduced as a result of publishing processes such as copy-editing and formatting may not be reflected in this document. For a definitive version of this work, please refer to the published source. Please note that access to the published version might require a subscription.

Chalmers Publication Library (CPL) offers the possibility of retrieving research publications produced at Chalmers University of Technology. It covers all types of publications: articles, dissertations, licentiate theses, masters theses, conference papers, reports etc. Since 2006 it is the official tool for Chalmers official publication statistics. To ensure that Chalmers research results are disseminated as widely as possible, an Open Access Policy has been adopted.

The CPL service is administrated and maintained by Chalmers Library. 


\title{
Ionic Liquids as Precatalysts in the Highly Stereoselective Conjugate Addition of $\alpha, \beta$-Unsaturated Aldehydes to Chalcones. ${ }^{* *}$
}

\author{
Linda Ta, ${ }^{[a] \ddagger}$ Anton Axelsson, ${ }^{[a] \ddagger}$ Joachim Bijl, ${ }^{[a]}$ Matti Haukka, ${ }^{[b]}$ and Henrik Sundén ${ }^{*[a]}$
}

\begin{abstract}
Imidazolium based ionic liquids (ILs) serve both as a recyclable reaction media and a precatalyst for the $\mathrm{NHC}$-catalyzed conjugate addition of $\alpha, \beta$-unsaturated aldehydes to chalcones. The reaction produces a broad scope of 1,6-ketoesters incorporating an anti-diphenyl moiety in high yields and with high stereoselectivity. In recycling experiments the IL can be reused up to five times with
\end{abstract}

retained reactivity and selectivity. Moreover, the 1,6-ketoesters form self-assembled organogels in aliphatic hydrocarbons. The reaction protocol is robust, easily operated, scalable and highly functionalized compounds can be obtained from inexpensive and readily accessible starting materials.

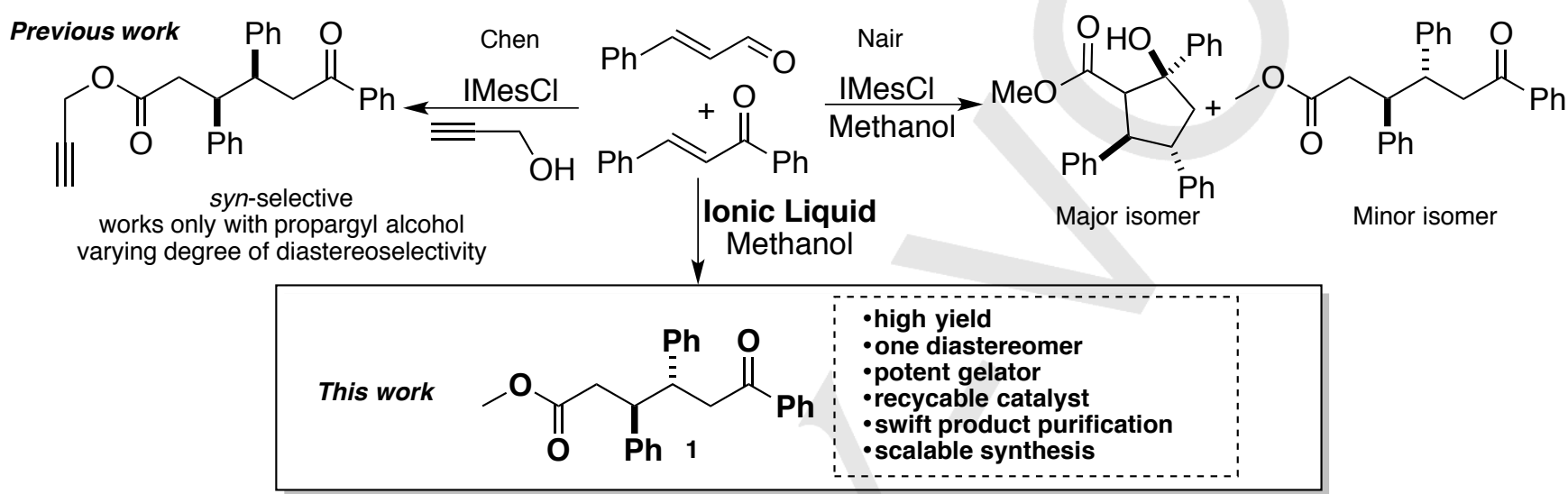

Scheme 1. NHC catalyzed three-component reactions involving chalcones, $\alpha, \beta$-unsaturated aldehydes and alcohols.

With an increasing demand for sustainable chemical production green chemistry has gained widespread attention in recent years. ${ }^{[1]}$ Central in green chemistry, and themes for this scientific report, are challenges such as atom efficiency, the use of catalytic rather than stoichiometric reagents and waste prevention. The latter, waste prevention, have motivated the use of ionic liquids (ILs) as reaction media in organic chemistry. ${ }^{[2]}$ ILs have unique solubility properties such as high stability, non-flammability and low volatility and can therefore easily be recovered and reused as reaction solvent. It is also possible to use ILs as catalysts. ${ }^{[3]}$ For instance, imidazolium-based ILs can be converted into their corresponding 1,3-dialkylimidazole-2ylidene, an N-heterocyclic carbene (NHC), by a single deprotonation. ${ }^{[4]} \mathrm{NHCs}$ derived from thiazolium, imidazolium and

[a] L. Ta, A. Axelsson, J. Bijl, Dr, H. Sundén* Chemistry and Biological Engineering Chalmers University of Technology Kemivägen 10, 41296 Gothenburg, Sweden E-mail: sundenh@chalmers.se

[b] Prof. M. Haukka

Department of chemistry

University of Jyväskylä

P.O. Box 35, FI-40014 University of Jyväskylä, Finland

** Generous support by The Swedish Research Council Formas and Magnus Bergvalls stiftelse are gratefully acknowledged. We thank Prof. Ann-Therese Karlberg (University of Gothenburg) and Maria Fridén-Saxin (Astra Zeneca) for the generous donation of glassware.

$\ddagger \quad$ These authors contributed equally to this work.

Supporting information for this article is given via a link at the end of the document. triazolium salts have emerged as an established catalytic method for making $\mathrm{C}-\mathrm{C}$ bonds in the field of organocatalysis. ${ }^{[5]}$ Although being a facile and inexpensive way of generating NHCs, the connection between ILs and C-C bond forming NHC-catalysis is rather poorly exploited. ${ }^{[6]}$ Nevertheless, it was recently shown that imidazoliumbased ILs could be used as precatalysts in NHC-catalyzed coupling reactions such as the benzoin condensation. ${ }^{[7]}$ For example, Davis et al. have used 1-N-alkyl-thiazoliums to catalyze the formation of benzoin from benzaldehyde. ${ }^{[7]}$ More recently, Chen and co-workers used 1-ethyl-3-methyl imidazolium acetate (EMIMAc) as a precatalyst in a benzoin-type condensation of 5hydroxymethylfurfural (HMF) to 5,5'-di(hydroxy-methyl)furoin (DHMF) ${ }^{[8]}$ Furthermore, NHCs derived from ILs have also been used in transesterifications ${ }^{[9]}$ and oxidative esterification of aldehydes. ${ }^{[10]}$ In NHC-catalysis, $\alpha, \beta$-unsaturated aldehydes are known to form a diverse set of catalytically generated homoenolate, enolate and acyl anion equivalents as intermediates, each one capable of supporting individual reaction paths. Thus, combinations of $\alpha, \beta$-unsaturated aldehydes, chalcone and different NHC-catalysts have to date generated several different types of annulation reactions as envisioned and presented by the groups of Bode, ${ }^{[11]} \mathrm{Chi}^{[12]} \mathrm{Nair}^{[13]}$ and Scheidt. ${ }^{[14]}$ In combination with an alcohol these reactions tend to form acyclic compounds (Scheme 1). In this respect, Nair and coworkers obtained anti-1,6-ketoesters as a byproduct in their synthesis of functionalized cyclopentanes. ${ }^{[13 \mathrm{~b}]}$ Recently, Chen and coworkers have reported the NHC-catalyzed formation of $\varepsilon$-ketoesters with a syn-oriented vicinal diphenyl using propargylic alcohols as a nucleophile. ${ }^{[15]}$ However, the level of chemo- and stereoselectivity observed in these reactions is rather low and may constitute a 
purification problem leading to time-consuming chromatography. Clearly a more selective method towards these types of highly functionalized compounds would be most desirable. In this paper we report a robust protocol for the highly stereoselective and high yielding NHC-catalyzed conjugate addition of $\alpha, \beta$-unsaturated aldehydes to chalcones to form highly functionalized 1,6-ketoesters incorporating an anti-oriented vicinal diphenyl. Furthermore, this reaction constitutes an excellent example of green chemistry, since the developed methodology is atom efficient, catalytic with respect to the $\mathrm{NHC}$-species and the ionic liquid/catalyst can be recovered and reused several times as well as obtaining the pure 1,6-ketoesters simply by filtration thereby eliminating time-consuming and solventdemanding chromatography. Moreover, the racemic 1,6-ketoesters form organogels in aliphatic hydrocarbons which is in stark contrast to the almost enantiopure product that does not gelate.

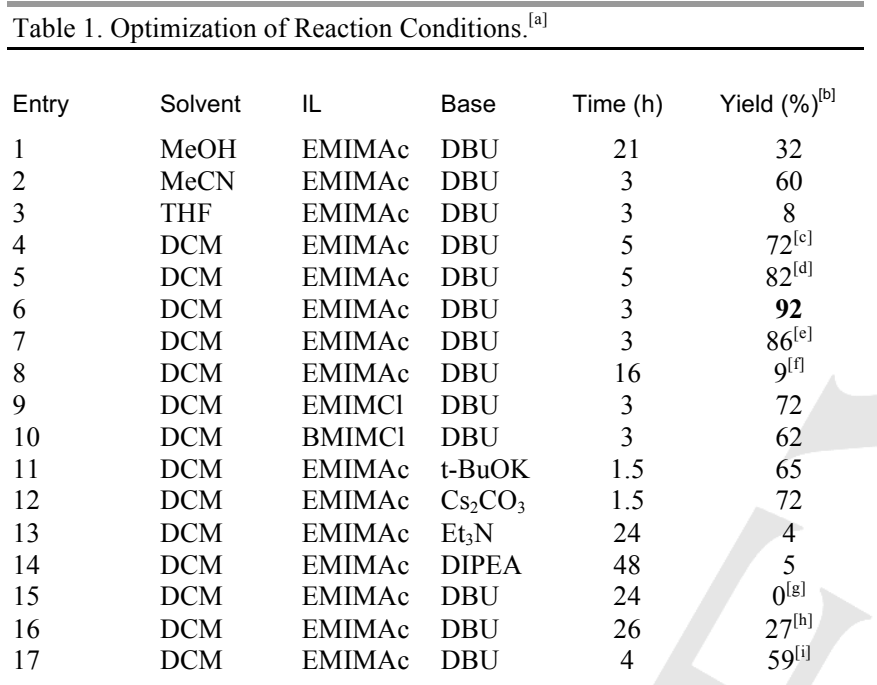

[a] Reactions performed at rt., 0.5 equiv. base, 2.5 equiv. IL, 3 equiv. cinnamaldehyde, 10 equiv. methanol. [b] isolated yield. [c] 1 equiv. of cinnamaldehyde. [d] 2 equiv. of cinnamaldehyde. e) gram-scale reaction, $1.1 \mathrm{~g}$ of $\mathbf{1}$ isolated. [f] 0.25 equiv. EMIMAc. [g] 0 equiv. methanol. [h] 1 equiv. methanol. [i] 15 equiv. methanol

Our initial attempts in neat IL showed that the conjugate addition of cinnamaldehyde to chalcone was highly stereoselective and gave the anti-1,6-ketoester 1 (Scheme 1) in moderate conversion due to poor solubility of $\mathbf{1}$ in IL, hence stopping the agitation of the reaction. This prompted the investigation of different co-solvents, it was found that solvents miscible with EMIMAc, such as methanol, acetonitrile and dichloromethane gave the best results (Table 1, entry 1,2 and 4). Attempts to replace dichloromethane with a more sustainable solvent failed for reasons of solubility of $\mathbf{1}$. The product is insoluble in all the investigated solvents except for dichloromethane. In the absence of dichloromethane, a precipitation forms during the reaction with a detrimental effect on the reaction yield. Performing the reaction with catalytic quantities ( 0.25 equiv.) of EMIMAc gives a sluggish mixture and 1 can be isolated in $9 \%$ yield (Table 1 , entry 8 ). ${ }^{[16]}$ The choice of the base is also important. Strong bases such as; $t-\mathrm{BuOK}$ and $\mathrm{Cs}_{2} \mathrm{CO}_{3}$ are efficient in this reaction providing ketoester 1 in $65 \%$ and $72 \%$ yield, respectively (Table 1, entries 11 and 12). However, an unidentified background reaction is active under these conditions and the chalcone is consumed within $1.5 \mathrm{~h}$.

Table 2. Scope of the Chalcones. ${ }^{[a]}$

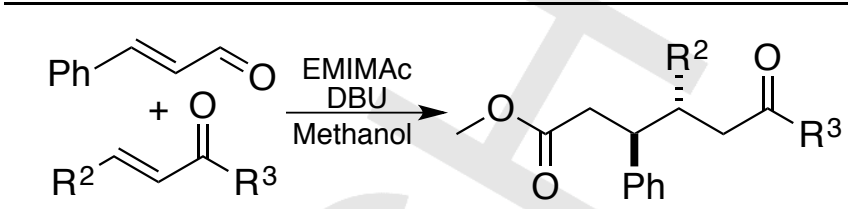<smiles>COC(=O)C[C@@H](c1ccccc1)[C@H](CC(=O)Pc1ccccc1)c1ccccc1C</smiles>

$266 \%$ yield[b] $20: 1 \mathrm{dr}$ 3h<smiles>COC(=O)C[C@H](c1ccc(C)cc1)[C@H](CC(=O)P)c1ccccc1</smiles>

$487 \%$ yield 20:1 dr $3 \mathrm{~h}$

$$
3 h
$$

$377 \%$ yield $20: 1 \mathrm{dr}$ $3 \mathrm{~h}$<smiles>COc1ccc([C@H](CC(=O)c2ccccc2)[C@H](CC(=O)Oc2ccccc2)Pc2ccccc2)cc1</smiles>

$574 \%$ yield $20: 1 \mathrm{dr}$ $4 \mathrm{~h}$<smiles>COC(=O)C[C@@H](c1ccccc1)[C@H](CC(=O)Pc1ccccc1)c1ccc(P)cc1</smiles>

$675 \%$ yield $20: 1 \mathrm{dr}$ $3 \mathrm{~h}$<smiles>[X]c1ccc(C(=O)CC(c2ccccc2)[C@H](CC(=O)OC)c2ccccc2)cc1</smiles>

$\mathrm{X}=\mathrm{Br}, 10$

$79 \%$ yield $20: 1 \mathrm{dr}$

$3 \mathrm{~h}$

[a] Reactions performed at rt., 0.5 equiv. base, 2.5 equiv. IL, 3 equiv. aldehyde, 10 equiv. methanol. [b] yields refer to isolated yields after purification.

The best results were obtained using DBU, with full conversion in $3 \mathrm{~h}$ to give 1 in $92 \%$ yield and 20:1 dr. (Table 1, entry 6). Weaker organic bases such as $\mathrm{Et}_{3} \mathrm{~N}$ and DIPEA perform less well and only gave trace amounts of product (Table 1, entries 13 and 14). Furthermore, the concentration of methanol is also important; running the reaction with 10 equiv. methanol gives the optimal results, with equivalents either above or below results in longer reaction times and lower yields 
(Table1, entry 1, 16 and 17). The IL EMIMAc is more reactive than EMIMCl and BMIMCl (Table 1, entry 9 and 10) by almost $20 \%$ indicating that the acetate anion may be of significance for reactivity ${ }^{[17]}$ The counter ion effect in NHC-catalysis has previously been reported both experimentally ${ }^{[18]}$ and theoretically. ${ }^{[19]}$ Of note, during the course of the optimization, the reaction showed to be highly stereoselective and only one diastereoisomer was found in the reaction mixtures. The stereochemistry was determined by $\mathrm{X}$-ray crystallography to conclude that the reaction gives the anti-oriented vicinal diphenyl (Figure 1). It is important to note that we only detect the acyclic anti-oriented vicinal diphenyl which is the same product that is found as the minor isomer observed in the investigations by Nair et al. ${ }^{[13 b][20]}$

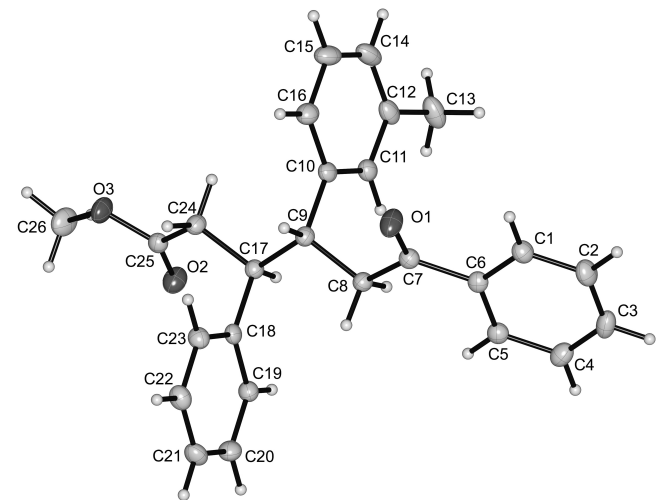

Figure 1. Ortep drawing of the anti-oriented vicinal diphenylethylene $3 .^{[21]}$

To survey the scope of the EMIMAc-mediated conjugate addition of $\alpha, \beta$-unsaturated aldehydes a variety of chalcones were evaluated, the results are summarized in Table 2 .

In general, aromatic chalcones are well tolerated in the reaction and the corresponding 1,6-ketoesters are formed in high yields and in one diastereomeric form only. Electron donating groups on the chalcone are well tolerated (entries 2-5). A halogen substituted chalcone (E)-3(4-bromophenyl)-1-phenylprop-2-en-1-one reacts with cinnamaldehyde to give 6 in $75 \%$ yield within $3 \mathrm{~h}$ of reaction time. A heteroaromatic chalcones was also employed although the yield was moderate (entry 7). Furthermore, the reaction worked well for different $\alpha, \beta$-unsaturated aldehydes retaining excellent diastereoselectivity and yield (table 3, entry 11-13). ${ }^{[22]}$ It should be noted that the para-methoxy substituted 12 formed in $67 \%$ yield requires much longer reaction time than any of the other 1,6ketoesters an effect previously been described in Cope rearrangements $^{[23]}$ (vide supra). With regard to the alcohol reaction partner ethanol and benzyl alcohol react to give the corresponding ethyl ester and benzyl ester in 53\% and $68 \%$ yield and $20: 1 \mathrm{dr}$, respectively (entry $\mathbf{1 4}$ and $\mathbf{1 5}$ ). It is notable that the only nucleophiles compatible with this reaction are primary alcohols as secondary and tertiary alcohols did not react and are probably too sterically hindered to take part in the assembling of the 1,6-ketoesters.

As the IL serves as the source of catalyst it of interest to see whether regeneration of the IL would affect the catalytic performance. Initially we subjected the reaction mixture to a water/dichloromethane extraction.

Table 3. Scope of the $\alpha, \beta$-unsaturated Aldehyde and Alcohol. ${ }^{[a]}$

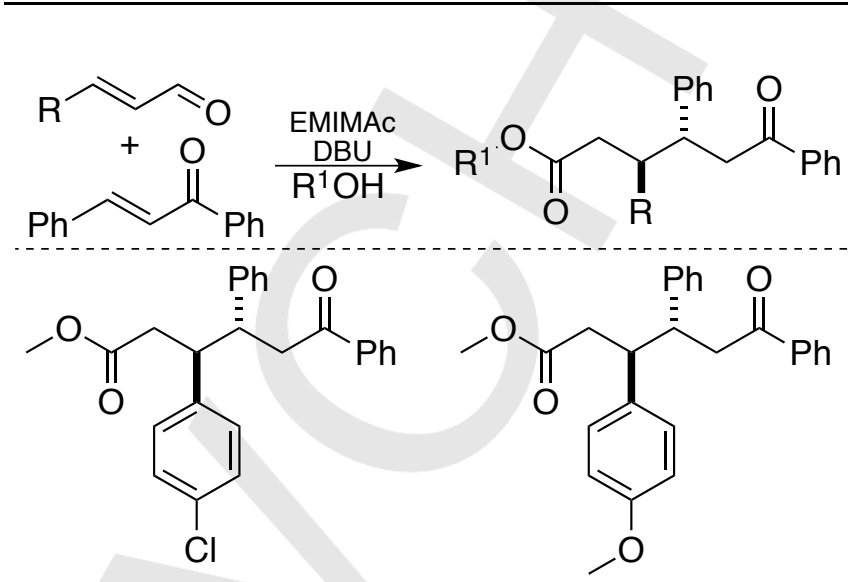

$1184 \%$ yield[b] $20: 1 \mathrm{dr}$ $3 \mathrm{~h}$<smiles>O=C([Hg])C[C@H](c1ccccc1)[C@H](CC(=O)c1ccccc1)c1ccccc1</smiles>

$1354 \%$ yield $20: 1 \mathrm{dr}$ $24 \mathrm{~h}$
14

$R^{1}=E t, 53 \%$ yield $20: 1 \mathrm{dr}$ $5 \mathrm{~h}$
$1267 \%$ yield

$20: 1 \mathrm{dr}$ 4 days
$\mathrm{R}^{1}$<smiles>O=C(C[C@H](c1ccccc1)C(CCO)c1ccccc1)c1ccccc1</smiles>

a] Reactions performed at rt., 0.5 equiv. base, 2.5 equiv. IL, 3 equiv. aldehyde, 10 equiv. methanol. [b] yields refer to isolated yields after purification.

However, this treatment led to decreased reactivity in subsequent runs. ${ }^{[24]}$ More fruitful was a protocol where the volatiles were removed in vacuo and the resulting solid was washed with methanol to directly render the pure product as a solid material. The IL could then be reused after evaporation of the methanolic solution. This procedure was repeated up to five times with no decrease in reaction yield (Table 4). ${ }^{[25]}$ Moreover, the reaction is suitable for scaling purposes and 1 can be isolated in $1.1 \mathrm{~g}, 86 \%$ yield (Table 1, entry 7). Notably, the product is isolated by simple filtration and washing of the solid to render a pure compound without any time-consuming, solvent-demanding chromatography needed.

Table 4. Recycling of EMIMAc.

$\begin{array}{lccccc}\begin{array}{l}\text { Times } \\ \text { recycled }\end{array} & 1 & 2 & 3 & 4 & 5 \\ \text { Yield }^{[a]} & 85 & 82 & 83 & 89 & 81\end{array}$

To each new run the recovered IL were added: 1equiv. of chalcone, 3 equiv. cinnamaldehyde, 0.5 equiv. DBU, 10 equiv. methanol. [a] isolated yield.

On the basis of the anti-configuration obtained in X-ray analysis of diphenyl 3 the following catalytic cycle is proposed: The catalytic 
cycle starts with addition of the NHC to the $\alpha, \beta$-unsaturated aldehyde to form the Breslow intermediate (I). The Breslow intermediate reacts reversibly in a cross-benzoin reaction with the chalcone to form diene (II). II undergoes an oxy-Cope rearrangement via a boat transition state (TS) setting the anti-oriented stereogenic centers (III). ${ }^{[26]}$ Tautomerization leads to acyl azolium IV. IV reacts with methanol to deliver the product regenerating the NHC-catalyst.

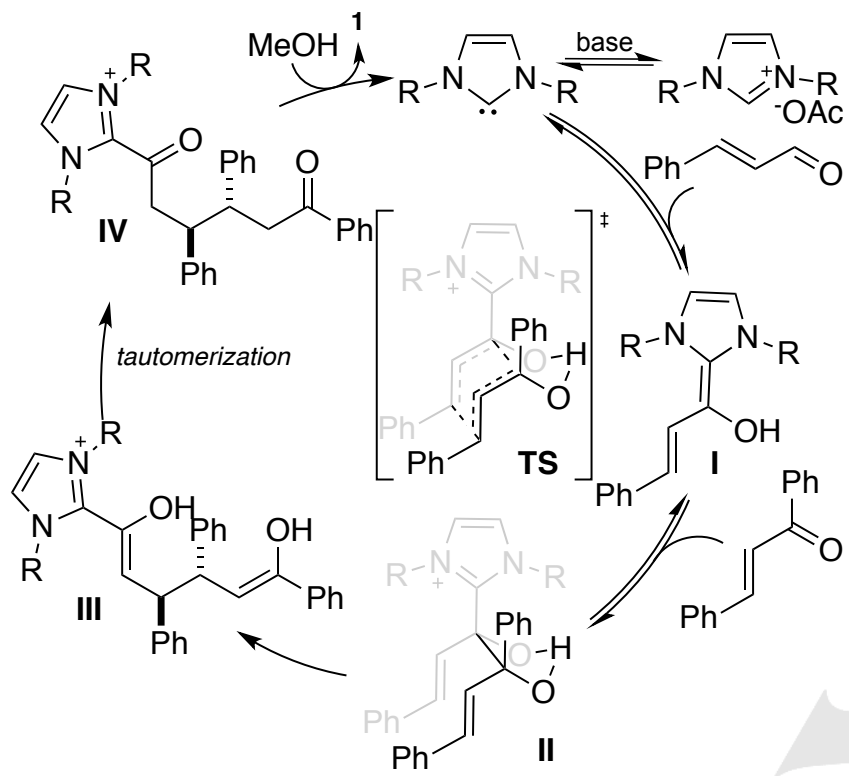

Scheme 2. Catalytic cycle of the NHC-catalyzed addition of chalcon to cinnamaldehyde $(\mathrm{R}=\mathrm{Me}, \mathrm{Et})$.

During the course of this investigation we discovered that the racemic 1,6-ketoesters form organogels in aliphatic hydrocarbons such as heptane and hexane (Figure 2). ${ }^{[27]}$ The gel formation is reversible and the gels can be redissolved in dichloromethane to provide the solvated 1,6-ketoesters. Further, the gelation is concentration dependent and compound 1 needs at least $2 \mathrm{mg} / \mathrm{ml}$ of heptane for the gelation to occur. At higher concentrations the gelation is fast and occurs within one minute after mixing. Moreover, in order to investigate the gelation event further, an almost enantiopure sample of 1' (97\% ee) was prepared (Scheme 3) and subjected to the same gelation conditions as for the racemic $\mathbf{1}$ and no gelation could be observed (See SI). ${ }^{[28]}$

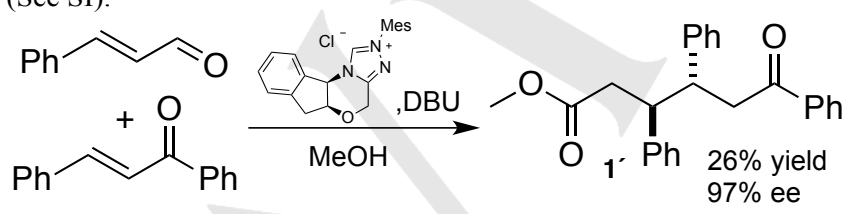

Scheme 3. Enantioselective syntesis of compound 1, ${ }^{[29]}$

This has led us to propose that a pair of enantiomers in contrast to a single enantiomer results in favourable $\pi-\pi$ interactions and van der Waals interactions leading to the self-assembly of the supramolecular network of the organogel.
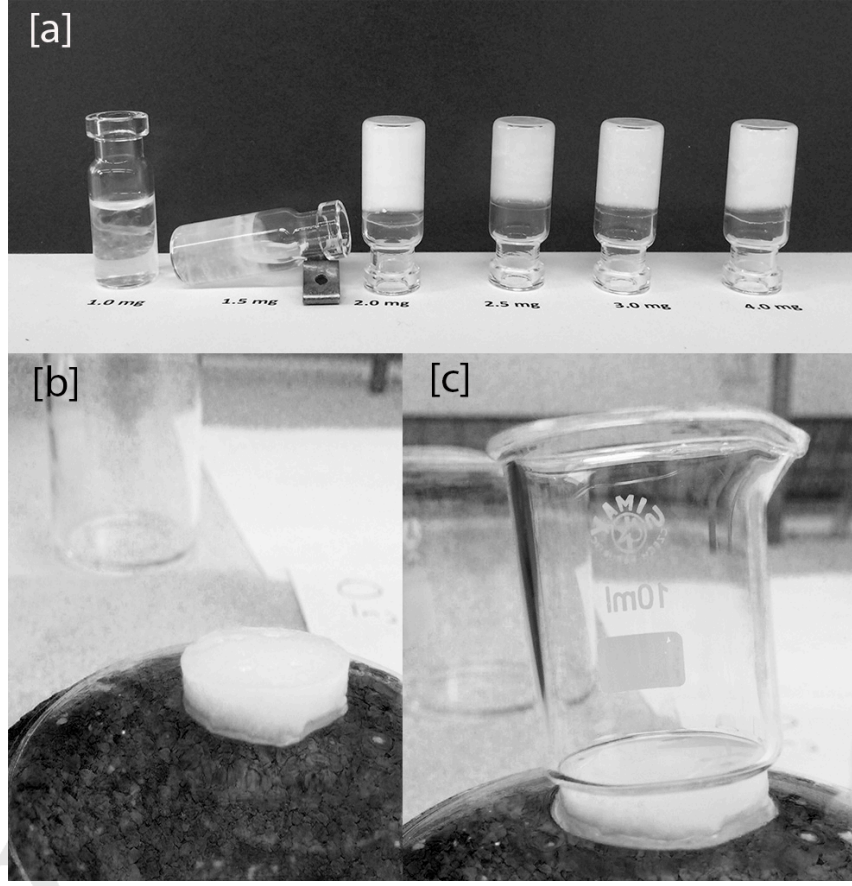

Figure 2. [a] Concentration dependence of 1 in the gelation. At concentrations above $4 \mathrm{mg} / \mathrm{mL}$ the gelation occurs within one minute after mixing. [b] Organogel removed from the formwork with retained shape. [c] The organogel is relatively tolerant towards pressure and can support the weight of a small beaker. At this pressure some heptane is pressed out of the gel but when the beaker is removed the gel regains its original shape.

To conclude we have achieved a highly stereoselective NHCcatalyzed addition of $\alpha, \beta$-unsaturated aldehydes to chalcones using commercial and inexpensive ionic liquids as precatalysts. The reaction is generally high yielding, has a broad substrate scope and excellent diastereoselectivities are obtained in all cases. Furthermore, the exclusive formation of the acyclic anti-stereoselectivity is independent of the substitution pattern of the reactants1, which distinguishes this work from the previous reports. ${ }^{[13 b, 15]}$ Moreover, the 1,6-ketoesters obtained, incorporating an anti-oriented vicinal diphenyl moiety, are rare in the sense that it is difficult to prepare these compounds using other approaches. In the lab, rheology experiments and a thorough investigation to establish a structuregelation-relationship is under investigation. Moreover, work focusing on a number of catalytic transformations involving NHCs generated from ILs as well as a complete mechanistic investigation of the role of $\mathrm{NHC} / \mathrm{IL}$ in stereoselective formation of 1,6-ketoesters is on-going.

Keywords: green chemistry $\bullet$ ionic liquid $\cdot \mathrm{NHC} \cdot 1,6$-ketoesters - organogels P. Anastas, J. Warren, Green Chemistry: Theory and Practice
Oxford University Press, 2000. 
[2] See, for example: a) T. Welton, Chem. Rev. 1999, 99, 2071-2084; b) J. P. Hallett, T. Welton, Chem. Rev. 2011, 111, 3508-3576; c) J. H. Davis, Jr., P. A. Fox, Chem. Commun. 2003, 1209-1212.

[3] See, for example: a) Q. Zhang, S. Zhang, Y. Deng, Green. Chem. 2011, 13, 2619-2637; b) J. H. Davis, Jr., Chem. Lett. 2004, 33, 1072 1077.

[4] See, for example: a) R. W. Alder, P. R. Allen, S. J. Williams, J. Chem. Soc., Chem. Commun. 1995, 1267-1268; b) Y.-J. Kim, A Streitwieser, J. Am. Chem. Soc. 2002, 124, 5757-5761; c) H. Chen, D. R. Justes, R. G. Cooks, Org. Lett. 2005, 7, 3949-3952; d) Y. Chu H. Deng, J.-P. Cheng, J. Org. Chem. 2007, 72, 7790-7793; e) M. Thomas, M. Brehm, O. Hollóczki, B. Kirchner, Chem. Eur. J. 2014, 20, 1622-1629.

[5] For reviews on NHC-catalysis, see: a) D. Enders, T. Balensiefer, Acc. Chem. Res. 2004, 37, 534-541; b) B. List, Acc. Chem. Res. 2004 37, 548-557; c) V. Nair, S. Bindu, V. Sreekumar, Angew. Chem. Int Ed. 2004, 43, 5130-5135; d) D. Enders, O. Niemeier, A. Henseler Chem. Rev. 2007, 107, 5606-5655; e) N. Marion, S. Díez-González, S. P. Nolan, Angew. Chem. Int. Ed. 2007, 46, 2988-3000; f) F. Glorius, Top. Organomet. Chem. 2007, 21, 1-20; g) A. T. Biju, N. Kuhl, F. Glorius, Acc. Chem. Res. 2011, 44, 1182-1195; h) J. L. Moore, T. Rovis, Top. Curr. Chem. 2010, 291, 77-144; i) X-Y. Chen $\mathrm{S}$. $\mathrm{Ye}$ in Stereoselective Organocatalysis: Bond Formation Methodologies and Activation Modes, (Ed, R. Rios) John Wiley \& Sons, Inc., 2013, pp 231-265.

[6] For examples of functionalized ionic liquids as organocatalysts, see: a) S. Luo, X. Mi, L. Zhang, S. Liu, H. Xu, J.-P. Cheng, Angew. Chem. Int. Ed. 2006, 45, 3093-3097; b) S. Luo, L. Zhang, J.-P. Cheng, Chem. Asian. J. 2009, 4, 1184-1195; c) D. E. Siyutkin, A. S. Kucherenko, S. G. Zlotin, Comprehensive Enantioselective Organocatalysis, (Ed. P. I. Dalko) Wiley-VCH Verlag $\mathrm{GmbH} \& \mathrm{Co}$. KGaA, 2013, Vol. 2, pp. 617-650; d) K. Zalewska, L. C. Branco, MiniRev. Org. Chem. 2014, 11, 141-153.

[7] a) J. H. Davis Jr, K. J. Forrester, Tetrahedron Lett. 1999, 40, 1621 1622; b) L.-W. Xu, Y. Gao, J.-J. Yin, L. Li, C.-G. Xia, Tetrahedron Lett. 2005, 46, 5317-5320; c) F. S. Jiang, H. Yu, G. Gao, R. G. Xie, Chin. Chem. Lett. 2005, 16, 321-324; d) J. Estager, J.-M. Lévêque, R. Turgis, M. Draye, J. Mol. Catal. A: Chem. 2006, 256, 261-264; e) J. Estager, J.-M. Lévêque, R. Turgis, M. Draye, Tetrahedron Lett. 2007, 48, 755-759; f) M. Orsini, I. Chiarotto, M. N. Elinson, G. Sotgiu, A. Inesi, Electrochem. Commun. 2009, 11, 1013-1017; g) M. H. Dunn, M. L. Cole, J. B. Harper, RSC Advances 2012, 2, 1016010162; h) Z. Kelemen, O. Holloczki, J. Nagy, L. Nyulaszi, Org. Biomol. Chem. 2011, 9, 5362-5364; i) F.-I. Yu, R.-I. Zhang, C.-x. Xie, S.-t. Yu, Tetrahedron 2010, 66, 9145-9150; j) A. Aupoix, G. VoThanh, Synlett 2009, 1915-1920. k) F.-L. Yu, J.-J. Jiang, D.-M. Zhao, C.-X. Xie, S.-T. Yu, RSC Advances 2013, 3, 3996-4000.

[8] D. Liu, Y. Zhang, E. Y. X. Chen, Green. Chem. 2012, 14, 2738-2746.

[9] a) G. A. Grasa, R. M. Kissling, S. P. Nolan, Org. Lett. 2002, 4, 35833586; b) R. Singh, R. M. Kissling, M.-A. Letellier, S. P. Nolan, J. Org Chem. 2003, 69, 209-212; c) G. A. Grasa, T. Güveli, R. Singh, S. P.
Nolan, J. Org. Chem. 2003, 68, 2812-2819; d) M. Feroci, I. Chiarotto, M. Orsini, R. Pelagalli, A. Inesi, Chem. Commun. 2012, 48, 53615363.

[10] a) G. Forte, I. Chiarotto, A. Inesi, M. A. Loreto, M. Feroci, Adv. Synth. Catal. 2014, 356, 1773-1781; b) I. Chiarotto, M. Feroci, G. Sotgiu, A. Inesi, Eur. J. Org. Chem. 2013, 2013, 326-331.

[11] P.-C. Chiang, J. Kaeobamrung, J. W. Bode, J. Am. Chem. Soc. 2007, 129, 3520-3521.

[12] a) Z. Fu, H. Sun, S. Chen, B. Tiwari, G. Li, Y. Robin Chi, Chem. Commun. 2013, 49, 261-263; b) Z. Fu, J. Xu, T. Zhu, W. W. Y. Leong, Y. R. Chi, Nat. Chem. 2013, 5, 835-839; c) W. W. Y. Leong, X. Chen, Y. R. Chi, Green Chem. 2013, 15, 1505-1508.

[13] a) V. Nair, S. Vellalath, M. Poonoth, E. Suresh, J. Am. Chem. Soc. 2006, 128, 8736-8737; b) V. Nair, B. P. Babu, S. Vellalath, V. Varghese, A. E. Raveendran, E. Suresh, Org. Lett. 2009, 11, 25072510.

[14] B. Cardinal-David, D. E. A. Raup, K. A. Scheidt, J. Am. Chem. Soc. 2010, 132, 5345-5347

[15] J. Ma, Y. Huang, R. Chen, Org. Biomol. Chem. 2011, 9, 1791-1798.

[16] Other NHC precatalysts were also investigated, see SI.

[17] The role of the acetate ion, from a reactivity point of view, is not clear at this stage.

[18] J. Kaeobamrung, J. Mahatthananchai, P. Zheng, J. W. Bode, J. Am. Chem. Soc. 2010, 132, 8810-8812.

[19] L. R. Domingo, J. A. Saez, M. Arno, Org. Biomol. Chem. 2014, 12, 895-904.

[20] This is indicative of that there are two reaction paths operating in Nairs system one leading to the trans-fused cyclopentane and one leading to the acyclic anti-oriented vicinal diphenyethylene.

[21] CCDC 1010853 (3) contains the supplementary crystallographic data for this paper. These data can be obtained free of charge from The Cambridge Crystallographic Data Centre via www. ccdc.cam.ac.uk/data_request/cif.

[22] Aliphatic enals are ineffective as reaction partners in this reaction.

[23] a) E. N. Marvell, T. H. C. Li, J. Am. Chem. Soc. 1978, 100, 883-888; b) D.-N. Lee, H. Kim, L. Mui, S.-W. Myung, J. Chin, H.-J. Kim, J. Org. Chem. 2009, 74, 3330-3334.

[24] N. L. Mai, K. Ahn, Y.-M. Koo, Process Biochem. 2014, 49, 872-881.

[25] Proton NMR of the recycled EMIMAc is fairly clean and identical to a sample of unused EMIMAc (see SI).

[26] Bode, see ref 11, has also suggested the possible reversible crossbenzoin reaction and subsequent oxy-Cope rearrangement.

[27] N. Zweep, J. H. van Esch, in Functional Molecular Gels, The Royal Society of Chemistry, 2014, pp. 1-29.

[28] J. Makarević, M. Jokić, Z. Raza, Z. Štefanić, B. Kojić-Prodić, M. Žinić, Chem. Eur. J. 2003, 9, 5567-5580.

[29] Due to competing background reactions the yield of 1' is low. See SI for efforts to optimize the enantioselective reaction. 
Entry for the Table of Contents (Please choose one layout)

\section{COMMUNICATION}

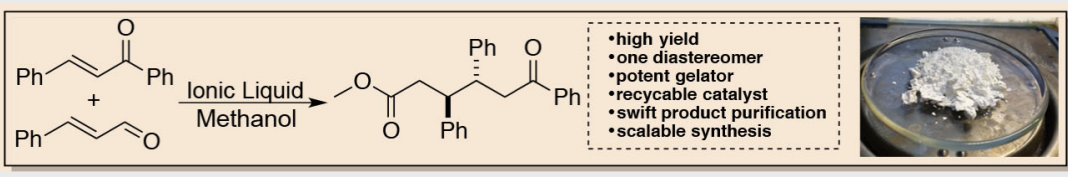

Breaking conventional standards: An excess of a recyclable ionic liquid NHCprecatalyst and focusing on racemic mixtures rather than enantioenriched, enabled us to reach new reactivity and selectivity in the reaction between chalcone and $\alpha, \beta-$ unsaturated aldehyde. The obtained racemic 1,6-ketoester contains an anti vicinal diphenyl moiety and has intriguing gelation properties, unlike the enantioenriched product that does not gel. The reaction is robust, simple and scalable, important for future application.
Linda Ta, Anton Axelsson, Joachim Bijl, Matti Haukka, Henrik Sundén*

Page No. - Page No.

lonic Liquids as Precatalysts in the Highly Stereoselective Conjugate Addition of $\alpha, \beta$-unsaturated

Aldehydes to Chalcones. 